Voix et Images

voixetimages

\title{
Les Murs de Montréal de J.-P. Filion
}

\section{Yannick Resch}

Volume 4, numéro 1, septembre 1978

Rina Lasnier

URI : https://id.erudit.org/iderudit/200144ar

DOI : https://doi.org/10.7202/200144ar

Aller au sommaire du numéro

\section{Éditeur(s)}

Les Presses de l'Université du Québec

\section{ISSN}

0318-9201 (imprimé)

1705-933X (numérique)

Découvrir la revue

Citer ce compte rendu

Resch, Y. (1978). Compte rendu de [Les Murs de Montréal de J.-P. Filion]. Voix et Images, 4(1), 146-147. https://doi.org/10.7202/200144ar d'utilisation que vous pouvez consulter en ligne.

https://apropos.erudit.org/fr/usagers/politique-dutilisation/ 


\section{Les Murs de Montréal de J.-P. Filion}

Avec les Murs de Montréal ${ }^{1}$ Jean-Paul Filion invite le lecteur à faire un voyage dans le temps - deuxième moment d'une odyssée qui remonte à l'enfance et dont Saint-André-Avellin, le premier côté du monde avait livré les premières expériences.

Dès le titre on comprend que cet itinéraire, cet apprentissage est semé d'embûches, d'obstacles, d'écrans liés à Montréal qui dresse ses “murs " devant les aspirations et les ambitions du narrateur. Mais les images d'une ville ne sont jamais pure représentation. Elles expriment moins un lieu que la situation de l'individu face à ce lieu. Ainsi Montréal est tantôt « un paradis avec des fumées colorées qui se baraudent partout, des airs de moteurs par centaines et du monde comme [il n'a] jamais vu ça ». (p. 16) Tantôt "un champ de bataille à n'en plus finir" (p. 324). Vocabulaire affectif, voire hyperbolique qui souligne que la ville est toujours perçue subjectivement à travers les passions et les tensions qu'elle engendre.

II ne faut donc pas s'attendre, en lisant ce récit de type biographique, à faire une "lecture" de Montréal. Certes, on y trouve surtout dans la première partie, à travers le regard d'un campagnard de quinze ans qui quitte son village pour venir travailler à la ville, l'approche globale de la grosse ville: “des maisons toutes collées, des automobiles toutes collées, des poteaux collés, le monde collé, assez qu'on ne pouvait pas voir le moindre petit trou nulle part» (p. 17). Le regard se pose sur un espace encombré, rempli à l'excès et qui ne laisse à celui qui observe aucune échappée sur un espace non utilisé. Quelques lieux sont décrits : ceux du travail, ceux du logement et les rues où ils se trouvent. Cette vision met surtout l'accent sur les valeurs vitales ou affectives qu'implique la ville bien plus que sur les traits architecturaux ou esthétiques : enthousiasme, ennui, dégoût, désir de fuir un lieu où l'on étouffe, où l'on s'aliène: «ma journée finie, je rentre mort dans ma chambre de la rue Sherbrooke. Je vais de temps en temps au port voir les bateaux qui partent... Ou au mont Royal me guérir l'âme en me collant contre les arbres" (p. 54). Fuir, ce sera retourner à Saint-André-Avellin, dans le cocon familial mais les «murs" ne sont ni dans la ville, ni dans le village. Le narrateur apprendra qu'il les porte en lui comme des enveloppes que l'adolescent doit faire éclater pour trouver sa voie et se réconcilier avec lui-même. 
Là réside l'intérêt du livre qui décrit les expériences multiples semées d'erreurs, d'échecs par lesquels il faut passer avant de devenir un être adulte; les rencontres qui modifient une destinée que l'on croyait tracée; les doutes et les certitudes l'amènent à constater que la vie est moins linéaire que répétitive, moins achèvement que recommencement: «Maintenant, c'est fini. Non, ça commence. Derrière Saint-Joachin, au bord du fleuve aux battures tapissées d'oies blanches, nous attend la plus belle maison du monde». (p. 431). Certes, cet "apprentissage" n'est pas en soi très original; d'autres auteurs l'ont fait et c'est un thème bien connu que celui du jeune garçon qui quitte sa campagne pour venir travailler à la ville; qui y fait son «éducation sentimentale» en même temps qu'il entreprend de grimper les échelons de l'échelle sociale. On regrettera parfois une certaine naïveté dans l'écriture qui réduit le lecteur au rôle de «consommateur» au lieu de lui laisser une marge de rêve. On lui apprend avec insistance quels sont les points forts de ce parcours : « $A$ quinze ans, en arrivant à Montréal j'ai connu l'enfance de la ville, puis ce fut celle de l'art. Maintenant on dirait que je me trouve devant celle de l'Amour... Chez Ledoux, dans ma chambre, un soir, j'écris dans mon cahier des pensées: "La vie est une suite d'enfances à n'en plus finir..." (p. 112). Et les points faibles sont de même expliqués au lecteur: à la fin du récit, alors que la situation présente est évoquée sans ambiguïté, le narrateur s'emploie à l'expliciter davantage par l'insertion dans sa narration d'un extrait d'une pièce qu'il est en train d'écrire et qui reproduit la crise familiale, «fidèle copie de ma réalité", personne n'en doute et l'on ne voit guère la raison d'être de ce second texte si ce n'est de tenir le lecteur au courant de la production littéraire de son auteur.

Ces faiblesses mises à part, le texte s'offre comme le témoignage d'une volonté de vivre, d'un refus de se complaire dans une douillette médiocrité. En cela il est stimulant parce que authentique dans la description que le narrateur fait de ses joies et de ses déceptions. Celui-ci ayant décidé “que la vie n'était pas faite pour reculer» (p. 77), prend des risques, remet en question ses activités, son métier et aussi sa vie affective. Cette famille qui s'est construite au fil du récit apparaît en fin de compte comme le dernier mur qu'il faut abattre. L'homme libéré de la dernière page est le résultat de ce lent travail et de ce livre qui, comme une analyse au sens psychanalytique du terme, a permis d'exorciser un pan du passé. Les petits textes en italique qui précèdent les différents moments de cet itinéraire sont là pour nous le rappeler.

Yannick Resch, Université d'Aix-Marseille.

1. Montréal, Leméac, 1977. 